\title{
Hong Kong needs a territory-wide registry for out-of-hospital cardiac arrest
}

\author{
CT Lui *, CL Lau, Axel YC Siu, KL Fan, LP Leung
}

\section{A B S T R A C T}

Out-of-hospital cardiac arrest (OHCA) is an urgent disease entity, and the outcomes of OHCA are poor. This causes a significant public health burden, with loss of life and productivity throughout society. Internationally, successful programmes have adopted various survival enhancement measures to improve outcomes of OHCA. A territory-wide organised survival enhancement campaign is required in Hong Kong to maintain OHCA survival rates that are comparable to those of other large cities. One key component is to establish an OHCA registry, such as those in Asia, the United States, Europe, Australia, and New Zealand. An OHCA registry can provide benchmarking, auditing, and surveillance for identification of weak points within the chain of survival and evaluation of the effectiveness of survival enhancement measures. In Hong Kong, digitisation of records in prehospital and in-hospital care provides the infrastructure for published on 10 Jun 2019 at www.hkmj.org. maintain a sustainable $\mathrm{OHCA}$ registry are necessary in Hong Kong as the first step to improve survival and outcomes of OHCA.

\begin{tabular}{l} 
Hong Kong Med J 2019;25:222-7 \\
\hline https://doi.org/10.12809/hkmj187661 \\
${ }^{1}$ CT Lui *, FHKCEM, FHKAM (Emergency Medicine) \\
${ }^{1}$ CL Lau, FHKCEM, FHKAM (Emergency Medicine) \\
${ }^{2}$ AYC Siu, FHKCEM, FHKAM (Emergency Medicine) \\
${ }^{3}$ KL Fan, FHKCEM, FHKAM (Emergency Medicine) \\
${ }^{4}$ LP Leung, FHKCEM, FHKAM (Emergency Medicine) \\
${ }^{1}$ Accident and Emergency Department, Tuen Mun Hospital, Tuen Mun, \\
Hong Kong \\
${ }^{2}$ Accident and Emergency Department, Ruttonjee Hospital, Wanchai, \\
Hong Kong \\
${ }^{3}$ Accident and Emergency Department, The University of Hong Kong- \\
Shenzhen Hospital, Shenzhen, China \\
${ }^{4}$ Emergency Medicine Unit, The University of Hong Kong, Pokfulam, \\
Hong Kong \\
* Corresponding author: luict@ha.org.hk
\end{tabular}

\section{Background}

Out-of-hospital cardiac arrest (OHCA) and sudden cardiac death (SCD) are significant healthcare challenges and public health burdens worldwide. ${ }^{1}$ It has been estimated that around half of cardiovascular mortalities present as SCD. ${ }^{2}$ Premature death may be caused by OHCA and SCD, particularly in cases involving children, adolescents, and young adults. The burden of premature death due to OHCA is on the magnitude of millions of years of potential life lost, and this is the third leading cause of years of potential life lost following cancer and heart disease. ${ }^{1}$

In Hong Kong, more than 5000 OHCA cases with attempted resuscitation occur annually. ${ }^{3}$ The incidence rate of OHCA in 2012 was reported to be 72 per 100000 population. Although the incidence is low, the prognosis of OHCA is generally poor. Worldwide, the survival rate of OHCA is $2 \%$ to $11 \%{ }^{4}$ In Hong Kong, a 2017 territory-wide study reported a survival rate of $2.3 \%$ and a neurologically favourable survival rate of $1.5 \%{ }^{3}$ Reported survival rates of OHCA in other parts of the world are heterogeneous, with $0.5 \%-8.5 \%$ reported in Asian countries, ${ }^{5} 8.5 \%$ in the US, ${ }^{6}$ and $10.3 \%$ in Europe. ${ }^{7}$ The survival rate of OHCA in Hong Kong is low compared with other cities or countries.

\section{Strategies to enhance out-of- hospital cardiac arrest survival}

To maximise the effectiveness of any efforts to improve OHCA outcomes, a well-organised territorywide survival enhancement campaign covering public, prehospital, and in-hospital resuscitative care for OHCA would be optimal. ${ }^{8,9}$ In the public dimension, fostering public awareness, enhancement of rate of good-quality bystander cardiopulmonary resuscitation (CPR), ${ }^{10}$ and a territory-wide public access defibrillation programme ${ }^{11}$ have been the main pillars of enhancement of survival of OHCA. In Hong Kong, there have been investigations on the availability and accessibility of defibrillators in the community.12,13 However, an organised public access programme is still lacking. In terms of prehospital and in-hospital measures, shorter response times of emergency medical systems, postresuscitation targeted temperature management, and comprehensive post-cardiac arrest care have proven to be effective measures to improve survival. ${ }^{8,14}$ A previous systematic review based mainly on observational data and small-scale trials suggested that prehospital epinephrine produced no improvement in rate of survival to hospital discharge..$^{15}$ A recently published large-scale trial 
demonstrated that epinephrine increased the rate of survival to hospital discharge while increasing the rate of severe neurological injury in survivors. ${ }^{16}$

\section{Need for a cardiac arrest registry}

Interpretation and comparison of survival rates of OHCA between cities is complicated by various factors, including variation in reporting mechanisms, reporting definitions, and prehospital care models, particularly the practice of prehospital termination of resuscitation at arrest scenes. The International Liaison Committee on Resuscitation has defined a standardised style of resuscitation outcome reports with definitions of parameters. ${ }^{17}$ The Utstein-style guidelines provide a standardised and harmonised framework for comparison and benchmarking of emergency medical services (EMS) systems. ${ }^{17,18}$ More importantly, epidemiological data on cardiac arrest provide insight about local systems for management of cardiac arrest and provide feedback to influence change in systems for enhancing survival. In 2010, the American Heart Association (AHA) recognised and reinforced the importance of data collection about OHCA and the establishment of cardiac arrest registries. The AHA identified and defined the essential core elements of a high-quality resuscitation system: measurement, benchmarking, and providing feedback for change. Experts have recommended that OHCA events become reportable events. ${ }^{19}$ In the last decade, there have been worldwide efforts to establish regional cardiac arrest registries in various cities and countries, including Japan, Singapore, South Korea, Sweden, and the United Kingdom. There have been collaborative registries in Asia (The Pan-Asian Resuscitation Outcomes Study), Europe (European Registry of Cardiac Arrest), the US (Cardiac Arrest Registry to Enhance Survival), and Australia, and New Zealand (Australian Resuscitation Outcomes Consortium epidemiological registry). As OHCA is an important public health burden, there is room for improvement in Hong Kong to enhance the survival rate of $\mathrm{OHCA}$, and there is scientific support for strategies and measures to improve the outcomes of OHCA. What is missing in Hong Kong is a wellorganised survival enhancement campaign, together with a territory-wide cardiac arrest registry. A

\section{香港需要成立院外心臟驟停登記處}

雷俊達、劉柱良、蕭粵中、㚞潔玲、梁令邦

院外心藏驟停 (OHCA) 屬急性疾病, 治療結果往往強差人意。這會 造成嚴重公共衛生負擔, 以及社會上生命和生產力的損失。國際上 有成功方案, 透過各種增強存活率措施改善OHCA的治療結果。香 港應實行全港性增強存活率措施, 以至其OHCA存活率與其他大城市 相若, 其一關鍵便是效法亞洲、美國、歐洲、澳洲和新西蘭等地成 立OHCA登記處。OHCA登記處可提供基準、審計和監督, 以識別生 存鏈中的弱點和評估增強存活率措施是否有效。在香港, 入院前和 院內護理記錄的數碼化為OHCA登記處提供運作基礎架構。作為改 善OHCA存活率和治療結果的第一步, 香港必須有良好資源和治理使 OHCA登記處可持續發展

cardiac arrest registry is a non-replaceable element of continuous surveillance, identification of weak points in the chain of survival, and evaluation of the effectiveness of newly implemented survival enhancement measures.

\section{Value of a cardiac arrest registry}

\section{As an indicator of the efficiency of emergency healthcare systems and for benchmarking}

The outcomes and survival rate of OHCA depend on the chain of survival (Fig). The survival rate and outcomes of OHCA are not performance indicators of prehospital EMS or emergency departments. Instead, it is a composite indicator of community resilience and effectiveness of EMS, advanced life support, and resuscitation in emergency departments and post-arrest cardiac and intensive care. The concept of community resilience, which has been supported by many experts in resuscitation science, had been raised in recent years in management of conditions where every second counts, such as OHCA. ${ }^{20}$ Early recognition and appropriate response by laypersons is the first and most critical step, including EMS activation, initiation of bystander CPR, and public access defibrillation. If these initial steps of recognition and resuscitation are not

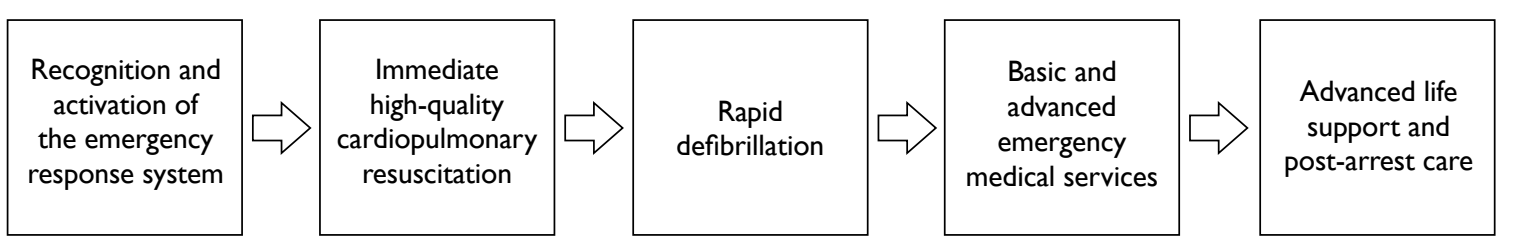

FIG. Chain of survival for out-of-hospital cardiac arrest 
performed well, profound hypoxic-ischaemic insult to the brain and other major organs is likely. No matter how hard the subsequent steps in the chain of survival are, and regardless of the sophistication of advanced and post-arrest care, the chance of survival and neurological integrity would be limited. Without a registry, the resilience of Hong Kong and the efficiency of its emergency healthcare system remain unclear.

\section{Surveillance, audit, and feedback}

The OHCA registry is a means of surveillance. The US Cardiac Arrest Registry to Enhance Survival (CARES) generates reports with trend analysis regularly. Any major changes in outcomes are identified, with corresponding investigation and rectification of any gaps. During audits, weak points of care in the chain of survival can be identified, which would provide invaluable information for the planning of a survival enhancement campaign. The AHA has recommended a complete audit cycle of (1) measurement by a cardiac arrest registry; (2) benchmarking; and (3) feedback and change. With the OHCA data, one could identify the weakest link in the chain of survival. Targeted survival enhancement measures can then be designed and implemented. For example, a local cardiac arrest registry at the accident and emergency department of Tuen Mun Hospital identified deficiencies in the availability and accessibility of publicly accessible defibrillators. ${ }^{12}$ With the implementation of survival enhancement measures, longitudinal data collected using the same collection methodology are required to evaluate their effectiveness.

\section{Evaluation of the effectiveness of survival enhancement measures}

Efficacy is the extent to which a treatment is capable of bringing about its intended effect under ideal circumstances. Most clinical trials nowadays have provided information on efficacy. However, the translation of the effects into clinical practice is not direct. Effectiveness is the extent to which a treatment achieves its intended effect in usual clinical settings in daily practice, which is addressed by studies with pragmatic design. Similar to numerous clinical conditions, most studies of OHCA evaluate efficacy instead of effectiveness. Effectiveness cannot be measured in controlled trials. The observational data in cardiac arrest registries constitute an important dimension to measure the effectiveness of survival enhancement measures. In the past decade, there have been numerous improvements in community engagement and prehospital and inhospital care for OHCA in Hong Kong. Community measures include the Heart-safe School Project by the Hong Kong College of Cardiology, ${ }^{21}$ mass CPR training organised by the Resuscitation Council of
Hong Kong, ${ }^{22}$ and the CPR training programme for secondary school students and domestic helpers by the Emergency Medicine Unit of the University of Hong Kong. Prehospital improvement measures have included universal application of external defibrillators, enhanced training of ambulance crews, widespread prehospital use of laryngeal mask airways, intravenous adrenaline, first dispatch firefighters, telephone CPR advice, and enhanced diversion policy for cardiopulmonary arrest. Inhospital innovations have included implementation of up-to-date advanced life support care guidelines, use of end-tidal capnography for CPR feedback, use of mechanical thumpers, extracorporeal CPR, and advancement in post-arrest intensive and cardiac care. So far, all reports of resuscitation outcomes of cardiac arrest in Hong Kong have been crosssectional. There are no longitudinal data reporting survival trends. An OHCA registry provides insights into the effectiveness of these measures in terms of changes in survival. The Japanese Nationwide public access defibrillation programme, which employs the All-Japan Utstein Registry of the Fire and Disaster Management Agency, recorded that the rate of neurologically favourable survival rose from $1.6 \%$ to $4.3 \%$ in 5 years. $^{11}$

\section{Experience with cardiac arrest registries in other cities and countries}

\section{The Pan-Asian Resuscitation Outcomes Study}

The Pan-Asian Resuscitation Outcomes Study (PAROS) collaborative network ${ }^{23}$ was established in 2010 with a prospective multicentre registry of OHCA events across the Asia-Pacific region. It was supported by the Singapore Clinical Research Institute and followed the CARES method. With input from the US Centers for Disease Control and Prevention (CDC), the PAROS database is CAREScompatible. The Asian Emergency Medical Services Council adopted the PAROS registry as one of its core activities. The PAROS network has now grown into a consortium of nine participating regions and countries: Australia, Japan, South Korea, Malaysia, Singapore, Taiwan, Thailand, Turkey, and the United Arab Emirates. The registry includes a population base of over 89 million. Each participating country is responsible for administering its own data collection process, and all data are input via a secure shared internet data capture system with a harmonised database hosted by the Singapore Clinical Research Institute. The goals of the network are to provide benchmarking against established registries, to generate best practice protocols for EMS systems, and to impact community awareness of emergency resuscitative care. 


\section{European Registry of Cardiac Arrest}

In 2007, the European Resuscitation Council initiated a campaign for Europe-wide collaboration on a European registry to record and analyse cases of cardiac arrest. The European Resuscitation Council set up a steering committee in 2008 focusing on the development of the European Registry of Cardiac Arrest (EuReCa), and its objective is to create a central quality management tool. ${ }^{24}$ The EuReCa collects data about resuscitative events episodically. The EuReCa ONE, which included 27 European countries, gathered all resuscitative events in October 2014.7 For EuReCa TWO, which covers resuscitation events from 1 October 2017 to 31 December 2017, data collection was completed by April 2018 and publication of results is pending.

\section{Cardiac Arrest Registry to Enhance Survival}

The CARES was funded by the US CDC, the Canadian Ontario Pre-hospital Advanced Life Support network, and the Resuscitation Outcomes Consortium of North America. ${ }^{25}$ Its governance is provided by the US CDC and the Emory University School of Medicine. It provides various platforms for input of standardised parameters about OHCA events by the participating states. The data sources include EMS providers, dispatch centres, and hospitals. The data are then merged into a single event representing a resuscitative episode. The registry provides a validated measurement tool with benchmarking capability for continuous quality improvement. It consolidates observations and conclusions from the collected data and publishes them in the form of a Morbidity and Mortality Report, ${ }^{6}$ and the scientific evidence is integrated into the AHA's resuscitation guidelines. The CARES was developed as a low-cost, high-impact public health surveillance system to identify the weakest links in the chain of survival in participating states.

\section{The Australian Resuscitation Outcome Consortium Australian and New Zealand out-of-hospital cardiac arrest Epistry}

The Australian Resuscitation Outcome Consortium (Aus-ROC) was established as a National Health and Medical Research Council Centres of Research Excellence in 2011. Its objective is to increase research capacity and improve OHCA survival and outcomes. Six previously established cardiac arrest registries in Australia and two in New Zealand contributed the data to form the Aus-ROC epidemiological registry (Epistry) in 2014. The Epistry represents approximately $63 \%$ of the Australian population (23.5 million) and $100 \%$ of the New Zealand population (4.5 million). The Epistry is coordinated and located at the Aus-ROC administrative base in the School of Public Health and Preventive Medicine at Monash University in Australia. Participating ambulance service networks are responsible for the data collection and upload through a webbased engine. An Epistry Management Committee was established to serve as the governing agent. Annual benchmarking reports are generated from the Epistry's data and provided to the ambulance services network and relevant bodies for continuous quality improvement.

\section{Technical and operational readiness for a cardiac arrest registry in Hong Kong}

Hong Kong is technically ready for the establishment of a territory-wide cardiac arrest registry. Clinical documentation in the prehospital and in-hospital settings would provide the basic technical infrastructure of the registry. Prehospital care for patients with cardiac arrest is provided almost exclusively by the ambulance service of the Fire Services Department, while the Government Flying Service and St John's ambulance service play a supplementary role. The prehospital documentation is digitalised in the electronic Ambulance Journey Record, where the parameters about cardiac arrest patients are standardised and Utstein-compatible. Together with electronic hospital databases and the electronic Accident and Emergency System project of the Hospital Authority, merging and integration of prehospital and in-hospital databases would provide a feasible infrastructure and backbone of the cardiac arrest registry in Hong Kong.

The establishment of cardiac arrest registries may be quite different from other existing healthcare registries in Hong Kong, such as the Hong Kong Cancer Registry ${ }^{26}$ and the Hong Kong Renal Registry. ${ }^{27}$ The cardiac arrest registries involve various stakeholders including emergency medical dispatchers, EMS systems, and acute hospitals. The specialties of acute hospitals include emergency departments, and intensive care, paediatric, cardiology and medical units. Expert input from academic units and professional bodies such as the Hong Kong Academy of Medicine and its Colleges, the Resuscitation Council of Hong Kong, and universities is desirable.

Governance and a well-defined operational framework of the OHCA registry are mandatory for sustainability and assurance of data quality. Referring to the experience with collaborative registries in the US, Europe, Asia, Australia, and New Zealand, it is reasonable to set up a registry governing and management committee whose role is to oversee areas such as setup, maintenance, data quality control, data privacy and security, and data use and access. The registry committee might be led by government bodies such as the Food and Health 
Bureau or co-governed with academic bodies such as the Hong Kong College of Emergency Medicine or universities. All relevant stakeholders should be involved in the registry committee. One key enabler of a sustainable registry is personnel to maintain it. With the digitisation of documentation in prehospital and in-hospital records, the gap requiring manual data entry and manipulation has been dramatically narrowed in recent years.

Setting up an OHCA registry alone does not improve outcomes of patients with SCD. Survival enhancement campaigns and strategies, perhaps led by the government, are required. A cardiac arrest registry should be considered a starting point that provides data to evaluate the effectiveness of measures adopted in survival enhancement campaigns and strategies and to provide uniform benchmarking for quality measurement.

\section{Conclusion}

With the growing public health burden of OHCA, Hong Kong has an imminent need to establish a territory-wide cardiac arrest registry. It can provide guidance and insight about the effectiveness of survival enhancement measures. It also provides uniform benchmarking for continuous quality improvement by both prehospital and in-hospital service providers. Concerted efforts by various stakeholders from the government, the Hospital Authority, and academia are necessary to make the registry a reality.

\section{Author contributions}

All authors contributed to the content of the review article, drafting of the manuscript, and critical revision for important intellectual content. All authors had full access to the data, contributed to the study, approved the final version for publication, and take responsibility for its accuracy and integrity.

\section{Conflicts of interest}

All authors declared no conflicts of interest.

\section{Funding/support}

This research received no specific grant from any funding agency in the public, commercial, or not-for-profit sectors.

\section{References}

1. Stecker EC, Reinier K, Marijon E, et al. Public health burden of sudden cardiac death in the United States. Circ Arrhythm Electrophysiol 2014;7:212-7.

2. Mehra R. Global public health problem of sudden cardiac death. J Electrocardiol 2007;40(6 Suppl):S118-22.

3. Fan KL, Leung LP, Siu YC. Out-of-hospital cardiac arrest in Hong Kong: a territory-wide study. Hong Kong Med J 2017;23:48-53.

4. Berdowski J, Berg RA, Tijssen JG, Koster RW. Global incidences of out-of-hospital cardiac arrest and survival rates: systematic review of 67 prospective studies. Resuscitation 2010;81:1479-87.

5. Ong ME, Shin SD, De Souza NN, et al. Outcomes for out-of-hospital cardiac arrests across 7 countries in Asia: The Pan Asian Resuscitation Outcomes Study (PAROS). Resuscitation 2015;96:100-8.

6. McNally B, Robb R, Mehta M, et al. Out-of-hospital cardiac arrest surveillance-Cardiac Arrest Registry to Enhance Survival (CARES), United States, October 1, 2005-December 31, 2010. MMWR Surveill Summ 2011;60:1-19.

7. Gräsner JT, Lefering R, Koster RW, et al. EuReCa ONE-27 Nations, ONE Europe, ONE Registry: a prospective one month analysis of out-of-hospital cardiac arrest outcomes in 27 countries in Europe. Resuscitation 2016;105:188-95.

8. Perkins GD, Lockey AS, de Belder MA, et al. National initiatives to improve outcomes from out-of-hospital cardiac arrest in England. Emerg Med J 2016;33:448-51.

9. Scottish Government. Scottish out-of-hospital cardiac arrest data linkage project: 2015/16-2016/17 results. Available from: https://www.gov.scot/publications/ scottish-out-hospital-cardiac-arrest-data-linkageproject-2015-16/pages/4/. Accessed 30 Sep 2018.

10. Wissenberg M, Lippert FK, Folke F, et al. Association of national initiatives to improve cardiac arrest management with rates of bystander intervention and patient survival after out-of-hospital cardiac arrest. JAMA 2013;310:137784 .

11. Kitamura T, Iwami T, Kawamura $\mathrm{T}$, et al. Nationwide public-access defibrillation in Japan. $\mathrm{N}$ Engl J Med 2010;362:994-1004.

12. Ho CL, Lui CT, Tsui KL, Kam CW. Investigation of availability and accessibility of community automated external defibrillators in a territory in Hong Kong. Hong Kong Med J 2014;20:371-8.

13. Fan KL, Lui CT, Leung LP. Public access defibrillation in Hong Kong in 2017. Hong Kong Med J 2017;23:635-40.

14. Lai $\mathrm{H}$, Choong $\mathrm{CV}$, Fook-Chong $\mathrm{S}$, et al. Interventional strategies associated with improvements in survival for out-of-hospital cardiac arrests in Singapore over 10 years. Resuscitation 2015;89:155-61.

15. Atiksawedparit P, Rattanasiri S, McEvoy M, Graham CA, Sittichanbuncha Y, Thakkinstian A. Effects of prehospital adrenaline administration on out-of-hospital cardiac arrest outcomes: a systematic review and meta-analysis. Crit Care 2014;18:463.

16. Perkins GD, Ji C, Deakin CD, et al. A randomized trial of epinephrine in out-of-hospital cardiac arrest. N Engl J Med 2018;379:711-21.

17. Perkins GD, Jacobs IG, Nadkarni VM, et al. Cardiac arrest and cardiopulmonary resuscitation outcome reports: update of the Utstein resuscitation registry templates for out-of-hospital cardiac arrest: a statement for healthcare professionals from a task force of the International Liaison Committee on Resuscitation (American Heart Association, European Resuscitation Council, Australian and New Zealand Council on Resuscitation, Heart and Stroke Foundation of Canada, InterAmerican Heart Foundation, Resuscitation Council of Southern Africa, Resuscitation Council of Asia); and the American Heart Association Emergency Cardiovascular Care Committee and the Council on Cardiopulmonary, Critical Care, Perioperative and Resuscitation. Resuscitation 2015;96:328-40. 
18. Jacobs I, Nadkarni V, Bahr J, et al. Cardiac arrest and cardiopulmonary resuscitation outcome reports: update and simplification of the Utstein templates for resuscitation registries. A statement for healthcare professionals from a task force of the International Liaison Committee on Resuscitation (American Heart Association, European Resuscitation Council, Australian Resuscitation Council, New Zealand Resuscitation Council, Heart and Stroke Foundation of Canada, InterAmerican Heart Foundation, Resuscitation Council of Southern Africa). Resuscitation 2004;63:233-49.

19. Nichol G, Rumsfeld J, Eigel B, et al. Essential features of designating out-of-hospital cardiac arrest as a reportable event: a scientific statement from the American Heart Association Emergency Cardiovascular Care Committee; Council on Cardiopulmonary, Perioperative, and Critical Care; Council on Cardiovascular Nursing; Council on Clinical Cardiology; and Quality of Care and Outcomes Research Interdisciplinary Working Group. Circulation 2008;117:2299-308.

20. Rea TD, Page RL. Community approaches to improve resuscitation after out-of-hospital sudden cardiac arrest. Circulation 2010;121:1134-40.

21. The Hong Kong Jockey Club Charities Trust. Hong Kong
College of Cardiology. The Jockey Club 'Heart-safe School' Project. Available from: http://www.heartsafeschool.org. hk/aboutus.aspx. Accessed 30 Sep 2018.

22. Resuscitation Council of Hong Kong. Useful information. The Jockey Club 'Heart-safe School' Project. Available from: http://www.rchk.org.hk/Useful_information.aspx. Accessed 30 Sep 2018.

23. Singapore Clinical Research Institute. About PAROS. Available from: https://www.scri.edu.sg/crn/pan-asianresuscitation-outcomes-study-paros-clinical-researchnetwork-crn/about-paros/. Accessed 30 Sep 2018.

24. Gräsner JT, Herlitz J, Koster RW, Rosell-Ortiz F, Stamatakis L, Bossaert L. Quality management in resuscitationtowards a European Cardiac Arrest Registry (EuReCa). Resuscitation 2011;82:989-94.

25. Cardiac Arrest Registry to Enhance Survival. myCARES. net. Available from: https://mycares.net. Accessed $30 \mathrm{Sep}$ 2018.

26. Xie WC, Chan MH, Mak KC, Chan WT, He M. Trends in the incidence of 15 common cancers in Hong Kong, 19832008. Asian Pac J Cancer Prev 2012;13:3911-6.

27. Leung CB, Cheung WL, Li PK. Renal registry in Hong Kong-the first 20 years. Kidney Int Suppl (2011) 2015;5:33-8. 